\title{
WORD DEAFNESS
}

\section{KATRINA DF HIRSCH, L.C.S.T. and JEANETTE JEFFERSON JANSKY}

The term "word deafness" has been used in the literature with reference to both children and adults; the present discussion is confined to word deafness in children.

The word-deaf child is entirely or partially unable to comprehend spoken language. In some of the milder cases all that can be observed is a time lag between reception and interpretation of the verbal. stimulus. There may or may not be difficulty in attaching meaning to sounds other than language such as the ring of the telephone or the bark of a dog. Occasionally there is trouble with localizatiøn of sounds. However, the disturbance is essen. tially on the verbal symbolic level and these children are often good at interpreting the inflection of the speaker's voice or his facial and bodily expression. The degree of expressive language impairment varies. Language may be non-existent, limited in quantity or poor in quality; jargon may be substituted for meaningful speech.

The diagnosis of word-deafness is appropriate only when significant peripheral auditory loss, mental retardation and psychopathology are ruled out as major contributory factors. Differential diagnosis is by no means always easy (particularly in the case of young children) and can be arrived at only by a process of elimination.

It was Kussmaul ${ }^{(8)}$ in 1877 who first coined the term "word-deafness" when referring to patients who had difficulty with comprehension of speech. Allen $^{(1)}$ in 1951 divided the historical development of the concept into four phases. During the first phase from 1828 to 1868 the tendency was (with only a few exceptions) to regard word-deaf children as idiots.

During phase two (from about 1868 to 1900) the expressive aspects of the disorder were emphasised, and Hale-White, Golding-Bird, Bastian and others described children who had a language all their own. During phase three, lasting through World War I, there, was a shift back to the receptive field.

During the fourth phase the study of traumatic aphasias resulting from the first world war gave new impetus' to these investigations. Wallin in 1927 first suggested that the disorder might be more widespread than was generally recognized.

Worster-Drought's(i3) description of the syndrome is basic to present understanding of the disorder. He said that these children's speech, once it develops, is monotonous, indistinct and often complicated by what he calls verbal apliasia. He feels that the disturbance is probably the result of a biological variation in the nature of an agenesis. Froeschels ${ }^{(5)}$ focusses interest mainly on the audi- tory inattention of word-deaf children and recommends therapy directed towards this aspect of the syndrome. In 1937 Orton ${ }^{(11)}$ drew attention to the hyperactivity of word-deaf children, also to their delay in developing a master hand. He was particularly interested in what he calls "developmental" word deafness - cases which did not show a reliable history of brain-injury but in whose family background there was ample evidence of various forms of language disability. Ewing's(4) study in 1940 showed that of 10 children who had been diag. nosed as word-deaf six had high frequency losses, thus pointing up the necessity for careful hearing evaluation. Nance ${ }^{(10)}$, in 1946, described intelli. gence evaluation of word-deaf children by means of tests not requiring comprehension and use of

language. In a report in 1950 Goldenberg ${ }^{(1)}$ (stimulated by Bangs' study done in 1948) did an exploratory investigation on 14 children said to be word-deaf, by comparing their performance with that of 10 "normal" youngsters and found that in. tellectual retardation, brain injury and regional hearing loss accounted for "numerous" cases diagnosed as being word-deaf. Carrell and Bangs ${ }^{(2)}$ in 1951 asserted that trouble with language comprehension was but one aspect of a more widespread syndrome and suggested that disturbed visuo-motor function, poor abstract performance, inferior figurebackground discrimination are worth while investi. gating. In a paper in 1952 de Hirsch ${ }^{(3)}$ took up some problems in differential diagnosis and drew attention to the fact that profound auditory inatten. tion, tendency to echolalia and paucity of language are features found both in word-deaf and in autis. tic children and that only prolonged clinical obser. vation of the child's total behaviour enables the clinician to discriminate between the two. She emphasized the fact that while not all word-deaf children show a positive electro-encephalogram or gross neurological signs, observation of their performance reveals perseveration, stimulus-bound behaviour, severe hyperkinesis and difficulty with control. In a later publication (3) ${ }^{(2)}$ stresses these children's basic Gestalt difficulties. Myklebust ${ }^{\left({ }^{(9)}\right.}$ in, his book published in 1951, throws light on behavioural symptoms of word-deaf children. He feels that their disturbance on the cortical level makes for difficulty with integration in most areas of functioning. Strauss ${ }^{(12)}$ in his very important contribution to the problem views word-deaf child. ren as brain-damaged. Brain injury, he says, results in poor development of basic sensory-motor schemata and thus leads to difficulty with language reception and expression. 
The latest (as yet unpublished) study in the field by Jansky ${ }^{(7)}$, who with de Hirsch investigated in detail 12 word-deaf children, points in the same direction. Diagnosis of word-deafness in this investigation was arrived at after other possible etiology had been ruled out. The audiograms of some of the children studied showed some incon. sistency. However, careful testing (including the psycho-galvanic skin resistance test) proved absence of a significant peripheral hearing loss in every single case, though some patients manifested marked delay in response to verbal stimuli. All of the 12 children were carefully evaluated as to intel. lectual potential. In addition to a quantitative analysis (the children's I.Q. ranged from dull normal to superior), they were analysed qualitatively. so as to assess functioning in areas other than language. All 12 cases were studied by signs of withdrawal or other psychopathology and only if it was possible to really reach the child was the diagnosis of autism ruled out. Jansky closely investigated the receptive aspect of language by testing the children's interpretation of both words and sentences. Inability to attend to verbal material, need for frequent repetition of linguistic stimuli, excessively short auditory memory span were all found to be of interest. The categories articulation, intelligibility, quantity of verbal output, pitch and rate were evaluated so as to assess the children's competence in terms of the expressive aspect of language. The children's body image, their perpetual, their motor and their visuo-motor performance were studied, as well as figure-ground discrimination. In addition, other "soft" neurological signs: evidence of disorganization, impulsiveness, distractibility, rigidity and perseveration, were noted. Laterality was evaluated in the framework of the child's ability to deal with spatial rela. tionships. The results of Jansky's study showed that in word-deaf children language deviations are accompanied by disturbances in other areas of functioning and suggest that their performance is similar to that found in youngsters with verifiable brain.injury.

Severe word-deafness is not a frequent syndrome. When it occurs there is often a history of anoxia, birth injury, haemorrhage, convulsions, or erhyroblastosis fetalis due to the $\mathrm{RH}$ factor. In cases where neurological and encephalographic tests are negative it has been usually inferred that one deals with what is generally called "developmental" word. deafness. However, Strauss' findings indicate that diffuse organicity can be inferred from severe motor area as well as from behavioural and lan. guage symptoms in the absence of a positive electro. encephalogram and gross (as opposed to soft) deviations in the percepetual-motor and visuo. neurological signs. One therefore feels inclined to assume that many of the cases diagnosed as "developmental" actually do present diffuse, nonfocal and probably mild organic signs on a central level.

The writers agree with Strauss that word-deaf children have trouble with fundamental sensory. motor-schemata. They feel that these youngsters' inability to respond to the highly complex patterns as they are presented in spoken speech is but one aspect of their difficulty with perceptual-motor and visuo-motor configurations. They have trouble structuring the perceptual field and experience speech in a diffuse, undifferentiated manner. The figure - be it the spoken word or the sentence does not stand out from the vast number of unorganised stimuli constantly impinging on the organism. Thus, words fail to have meaning. The word-deaf child's attempts at speech-monotonous, indistinct, formless and slurred, reflect equal diff. culty in organization and differentiation.

From these theoretical assumptions certain con. clusions can be drawn for therapy:

1. While word-deafness in severe form is a rare occurrence, it is probably insufficiently recog. nized that a relatively large number of children referred for dyslalia suffer from mild, receptive language disturbances - even where there is no significant peripheral hearing loss. Failure to recognize that the resulting paucity of lan. guage, the paragrammatism and the poor motor speech patterns have a receptive basis, results in wasteful and ineffective therapeutic efforts.

2. Inconsistent audiograms are fairly typical for word-deaf children.

3. A time lag in response to auditory stimuli is not always due to a hearing deficit, nor is it necessarily an indication of mental retardation. It might occur as part of the word.deaf syndrome and represent difficulty with differentiation and integration of the essential feature of an auditory experience.

4. Since the latest studies have shown that hyperkinesis and distractibility are important features of the syndrome (many of these children are explosive and disorganized) it would follow that they need help with structuralization of their environment. The number of stimuli has to be reduced, and a relatively simple frame of reference has to be set up before language training can be undertaken.

5. Since it is assumed that these children's diff. culty is primarily one of organization of complex auditory configurations, the cutting down of these configurations into shorter units is thus a prerequisite of treatment. Speech must also be slowed up, dramatized in actual life situations. Constant repetition of verbal stimuli is needed to facilitate the integration of the material of experience with the linguistic symbols representing them. 


\section{BIBLIOGRAPHY}

(1) Allen, I. "The History of Congenital Auditory Imperception" The 274; June 1952 .

(2) Carrel, James and Bangs, Jack. "Disorders of Speech Comprehension Associated with Idiopathic Language Retardation." The Nervous Child, 9: 64-76; 1957.

(3) He Hirsch Katrina. "Developmental Word Deafness De Firsch, Katray." Bulletin of the Ortun Society. and Specch Therapy. .'Gestalt Psychology As Applied 3: 11-20: April 1953. "Gestalt Journal of Nervous and to Lan Diseases, Vol. 120, Nos. 3: 4, 1954.

(4) Ewing, Alex, Differential University Press, 1940.

(5) Froeschels, Emil. "Pure Word Deafness in a Child (Auditory Verbal Agnosia Nielsen) "The Quarterly Auditory of Cnild Behaviour, 1: 228-240; April 1949.

(6) Coldenberg. Samuel. "An Exploratory Study of some Aspects of Idiopathic Language Retardation. "The Journal of Speech and Hearing Disorders, 15: 221-233, September 1900 .

(7) Jansky, Jeanette. "Word Deafness Viewed as One Jansky, Jeanette. "Word Deafness viewed as One Aspect of An Inclusive Syndrome."
(8 Kugsmaul "Die Storungen der Sprache," Ziemssen's Irandbuch der Speziellen Pathologie und Therapie 1877.

(9) New York: Grune and Stratton, 1964, 380p.

(10) Nance Lorna. "Differential Diagnosis of Aphasia in Nance Lorna. "Differential Diagnosis of Aphasia in 223: September 1946.

(11) Orton, Samuel, Reading, Writing and Speech Problems in Chisdren. New York: W. W. Norton and Company, Incorporated, 1957, 215p.

(12) Strauss, Alfred. "Aphasia in Children." American Journal of Physical Medicine, 32, 93-99, 1954.

Journal of Physical Medicine, Newell. Psychopathology Strauss, Altred and Kephast, Newell. Psychopathology and Edueation of the Brain-Injured Child. (Volum II) New York: Grune and Stratton, 1955, 267p. Strauss, Alfred and Lehtinen, Laura. Psychopatholofy and Education of the Brain-Injured Child... New York: Grune and Stratton, 1950, 220p.

(13) Worster-Drought, c. "Congenital Auditory Imperception (Congenital Word Deafness) and its Relation to Idioglossia and Allied Speech Defects." The Medical Press and Circular, 210, 411-417. 